\title{
AS RELAÇÕES DE GÊNERO NO ENSINO FUNDAMENTAL I: UMA ANÁLISE DA PRODUÇÃO ACADÊMICA EM EDUCAÇÃO FÍSICA
}

\author{
Nathalia Chaves Gomes, Universidade Estadual de Campinas - UNICAMP, Campinas, \\ São Paulo-Brasil \\ Márcia Orlando Moreno, Universidade Estadual de Campinas - UNICAMP, Campinas, \\ São Paulo - Brasil \\ Helena Altmann, Universidade Estadual de Campinas - UNICAMP, Campinas, São Paulo \\ - Brasil
}

\section{RESUMO}

Um dos grandes desafios enfrentados pelas/os professoras/es de Educação Física em sua prática refere-se ao trabalho com turmas mistas. Embora os estudos de gênero sejam uma área consagrada no Brasil, as pesquisas sobre Ensino Fundamental I ainda em pequeno número. Desta forma, o objetivo deste estudo foi investigar e analisar a produção acadêmica sobre as relações de gênero no ensino fundamental I (7 a 10 anos), a partir da análise de teses e dissertações disponíveis nas bibliotecas de algumas das principais universidades do país. Foram localizadas cinco analisadas a partir de três unidades de análise, a saber: "conteúdos e as relações de gênero", "diferenças nas habilidades corporais" e "relações de gênero: possibilidades de intervenção. Notamos carência de produção de conhecimento em relação as danças, lutas, ginásticas e esportes que não sejam o futebol. Em relação à intervenção pedagógica, os estudos apontam a diversificação dos conteúdos como um caminho para o rompimento das fronteiras de gênero. Cabe ao professor/a buscar estratégias para não reproduzir ou reafirmar preconceitos e discriminações, entendendo que existem diferenças nas habilidades corporais, mas essas necessitam ser respeitadas e compreendidas como na sua maioria culturalmente e sem justificar a submissão de um sexo em detrimento do outro.

Palavras-Chaves: Educação Física; Gênero; Séries iniciais; Ensino fundamental I.

\section{GENDER RELATIONS IN THE ELEMENTARY SCHOOL: AN ANALYSIS OF THE ACADEMIC PRODUCTION IN PHYSICAL EDUCATION}

\begin{abstract}
A major challenge faced by teachers even ladies or gentlemen Physical Education in their practice refers for working with mixed groups. Although gender studies is an are devoted in Brazil, research on elementary school I are still few in number. Thus, the aim of this study was to investigate and analyze the scholarship on gender relations in elementary school (7-10 years) from the analysis of theses and dissertations available in the libraries of some major universities in the country. The survey located five which were investigated from three units of analysis, namely, "content and gender relations", "differences in physical abilities" and "gender relations: possibilities of intervention". We noted the lack of production of knowledge about the dances, wrestling, gymnastics and sports other than soccer. Regarding the pedagogical intervention, studies show that diversity of content as a way to break the boundaries of genre. It is the teacher looking for strategies to play or not
\end{abstract}


to reaffirm prejudices and discrimination, understanding that there are differences in physical abilities, but these need to be respected and understood as constructed largely culturally and without justifying the subordination of one sex over another.

Key-Words: Physical Education; Gender; Initial series; Elementary I.

\section{RELACIONES DE GÉNERO EN LA ESCUELA PRIMARIA: UN ANÁLISIS DE LA PRODUCCIÓN ACADÉMICA EN EDUCACIÓN FÍSICA}

\section{RESUMEN}

Un gran desafío que enfrentan profesores de educación física en su práctica se refiere a trabajar con grupos mixtos. Aunque estudios de género es un área dedicada en Brasil, la investigación sobre la escuela primaria todavía pocos en número. Por lo tanto, el objetivo de este estudio fue investigar y analizar la beca en relaciones de género en la escuela primaria (7-10 años) a partir del análisis de las tesis y disertaciones disponibles en las bibliotecas de algunas de las principales universidades del país. Encontramos cinco analizados a partir de tres unidades de análisis, a saber: "Las relaciones de contenido y de género", "las diferencias en las capacidades físicas" y "lãs relaciones de género: oportunidades para la intervención. Hemos observado la falta de producción de conocimiento sobre las danzas, lucha, gimnasia y otros deportes que el fútbol. En cuanto a la intervención educativa, los estudios demuestran la diversificación de los contenidos como una forma de romper los límites del género. Es el maestro desarrollar estratégias para no jugar o reafirmar prejuicios y la discriminación, entendiendo que hay diferencias en habilidades físicas, pero estos deben ser respetados y comprendidos como los más culturalmente y sin justificar presentación de un sexo sobre otro.

Palabras-Clave: Educación Física; Gênero; Serie inicial; Escuela primária. 


\section{INTRODUÇÃO}

A Educação Física escolar passou por muitas transformações, especialmente a partir da década de 1980, surgindo diversas tendências em oposição ao modelo mecanicista, tecnicista e esportivista e, que, de algum modo, têm influenciado a formação e a prática pedagógica dos profissionais de Educação Física escolar. ${ }^{1}$

Estes movimentos da Educação Física, derivaram de debates da Educação em geral, que buscam o reencontro da escola com os vínculos perdidos entre educação e humanização, assumindo a formação do cidadão para sua intervenção na vida pública e fortalecendo a concepção democrática, na revitalização do pensamento pedagógico Nesse sentido, a Lei de Diretrizes e Bases de 1996, ${ }^{2}$ bem como os Parâmetros Curriculares Nacionais - PCNs, ${ }^{3}$ abrem espaço para uma escola comprometida com a cidadania, princípio da Inclusão e a igualdade de direitos. ${ }^{4}$

Como alerta Sousa e Altmann ${ }^{4}$ para que essas idéias e valores se tornem realidade na Educação Física escolar, não basta incluí-los em leis e nas propostas curriculares, é preciso, de acordo com Arroyo $^{5}$ citado por elas, que a escola se situe na construção de um projeto político e cultural por um ideal democrático que reflita, ao mesmo tempo, a complexa diversidade de grupos, etnias, gêneros, demarcado não só por relações de perda, de exclusão, de preconceitos e discriminações, mas também por processos de afirmações de identidades, valores, vivências e cultura.

Observando a realidade, notamos que tais leis e discursos nem sempre são concretizados, havendo muitas contradições. Uma dessas contradições situa-se na questão de gênero.

Souza Junior e Darido, ${ }^{6}$ afirmam que um dos grandes desafios enfrentados pelas/os professoras/es de Educação Física em sua prática refere-se à adoção de uma postura adequada para o trabalho com turmas mistas. Muitos optam por separar meninas e meninos durante as atividades e ainda diferenciam as atividades de acordo com o sexo. E há uma incorporação disso pelos alunos e alunas.

"O simples fato de se juntar meninos e meninas não garante uma revisão de preconceitos e discriminações presentes em nossa sociedade". Todavia, o meio para superá-los passa, 
principalmente, pelo convívio entre meninos e meninas, mediado pelo/a professor/a, no qual a intervenção deve favorecer a adoção de atitudes que conduzam ao reconhecimento e ao respeito às diferenças. ${ }^{7}$

Ilustrando tais conclusões e justificando a escolha pela temática de gênero, será exposta a experiência escolar de uma das autoras desta pesquisa, lembranças do tempo de aluna, que foram marcantes para a escolha deste estudo.

Durante o ensino primário (Ensino Fundamental I), entre 1994 a 1998, a Educação Física ainda era considerada uma atividade, ou seja, não fazia parte do currículo escolar como disciplina e não havia aulas com um professor/a especialista. Apenas em alguns momentos, a professora regente ou "de sala", quando os/as alunos/as comportavam-se, levava-os à quadra para brincar, mas com separação de meninas e meninos. Os meninos brincavam de futebol e as meninas brincavam de "coisas de meninas", por exemplo: pular corda, boneca, brincadeiras de roda, jogos de mãos, danças, dentre outras.

Ela sempre participava de jogos e brincadeiras ditas "masculinas", seus familiares e amigos sempre diziam "isso é coisa de menino e não de menina". Como adorava praticar tais atividades, não entendia porque meninas não poderiam participar de tais atividades, pois tinha facilidade e divertia-se.

Já naquela época, tal fato causava indignação à autora que, na maioria das vezes, queria brincar com os meninos e, quando conseguia que eles a aceitassem para jogar, tentava mostrar-se "forte". Numa determinada ocasião, no meio de um jogo de futebol, um colega chutou a bola em sua "barriga" e, devido à intensidade que a bola fora arremessada, a autora sentiu muita dor e perdeu a respiração por alguns instantes. No entanto, para que não a excluíssem do jogo pelo fato de ser menina, suportou a dor, "engoliu" o choro e afirmou que estava tudo bem.

Os anos se passaram e a partir do Ginásio (Ensino fundamental II) passou a ter aulas específicas de Educação Física, entretanto, também separada por sexo, quando as meninas aprendiam o handebol com uma professora e os meninos futebol com um professor, ou seja, conforme se verifica no modelo tradicional de ensino, com conteúdos limitados e sem 
considerar a opinião das/os alunas/os, para que vivenciassem outras práticas da cultura corporal de movimento e oportunidades iguais para ambos os sexos.

Atualmente, nota-se uma grande mudança nos discursos da Educação Física escolar, surgindo novas propostas pedagógicas conhecidas como renovadoras. Observamos que, no que se refere à discussão de gênero, existem muitas referências bibliográficas que apresentam reflexões favoráveis à inclusão. No entanto, parece-nos que no cotidiano das aulas de Educação Física, ainda prevalecem as discriminações e preconceitos.

Conforme aponta $\mathrm{Wenetz}^{8}$ há muitas pesquisas relacionadas à infância e à educação em várias áreas de pesquisa, no entanto, a maioria delas abordam temas como o desenvolvimento cognitivo, motor e afetivo da criança, os comportamentos em espaços escolares ou conteúdos escolares e propostas pedagógicas, predominantemente na educação infantil (que compreende de 0 a 6 anos) ou aproximadamente dos doze até a adolescência. Entretanto, conforme revisão bibliográfica realizada por Ileana Wenetz ${ }^{9}$ parece ter sido praticamente esquecidas as idades compreendidas entre os 7 e 11 anos.

Cruz ${ }^{10}$ também destaca a dificuldade na bibliográfica nacional sobre o tema, enfatizando a urgência de pesquisas de 7 a 10 anos e suas experiências nas relações de gênero.

Pereira ${ }^{11}$ constata que há uma escassez de trabalhos acadêmicos que tratem sobre a questão de gênero e a maior parte foi produzida recentemente, a partir de 2000, além de destacar a contemporaneidade do tema (TELLES ${ }^{12}$ citado por PEREIRA ${ }^{11}$ ). Fernandes, ${ }^{13}$ Silva $^{14}$ e Telles ${ }^{12}$ citados por Pereira ${ }^{11}$ também relatam a dificuldade de encontrar estudos sobre a questão gênero com essa faixa etária, de 7 a 10 anos.

Portanto, o objetivo deste estudo foi investigar e analisar a produção acadêmica sobre as relações de gênero no ensino fundamental I (7 a 10 anos). Alguns sistemas de ensino adotam a ampliação do ensino Fundamental I, onde os alunos iniciam com 5 ou 6 anos e finalizam com 10 ou 11 anos, no entanto, nesta pesquisa utilizaremos como referência as teses e dissertações levantadas, que devido ao período em que foram escritas, compreendem o ensino fundamental I, com o inicio aos 7 e termino aos 10 anos. A análise da produção bibliográfica sobre essa temática suscitou questões como: "Como e quais 
conteúdos devem ser desenvolvidos nas aulas Educação Física do ensino fundamental I para contribuir na ressignificação de estereótipos e preconceitos relacionados à questão de gênero? Quais estudos estão sendo desenvolvidos pelos estudiosos sobre o tema gênero na faixa etária estudada? Quais questões tais estudos tais pesquisas apontam no que se refere a estratégias de intervenções que considerem as questões de gênero?

A fim de responder tais perguntas, utilizamos o conceito de gênero como categoria de análise. Tal conceito, utilizado pela primeira vez por Gayle Rubin, ${ }^{15}$ consolidou-se como uma categoria de análise no Brasil principalmente através do artigo da historiadora norteamericana Joan Scott ${ }^{16}$ : "Gênero uma categoria útil de análise histórica", publicado pela primeira vez em 1986. Esse conceito rompe significativamente com a noção de que exista um único jeito masculino ou feminino de ser. ${ }^{17}$

\section{METODOLOGIA}

Nesta pesquisa foi realizada uma revisão bibliográfica de caráter qualitativo e exploratório, ${ }^{18}$ focando o aprimoramento do tema em questão.

Foi feito um levantamento de teses de doutorado e dissertações de mestrado relacionadas ao tema desta pesquisa, defendidas nos últimos dez anos. Tal levantamento foi realizado nas bibliotecas das seguintes universidades: Universidade Estadual de Campinas (UNICAMP), Universidade Estadual Paulista (UNESP), Universidade de São Paulo (USP), Pontifícia Universidade Católica de São Paulo (PUC-SP) e Universidade Federal do Rio Grande do Sul (UFRGS), foram relacionadas as quatro principais universidades de São Paulo e a UFRGS devido a sua tradição na produção acadêmica neste tema. $\mathrm{O}$ levantamento foi realizado no segundo semestre de 2010.

Para realizarmos a pesquisa nas bibliotecas dessas universidades utilizamos as seguintes palavras chaves: gênero; educação física; séries iniciais; ensino fundamental I; meninos e meninas; crianças. Os resultados quantitativos desta pesquisa aparecem na Tabela 1: 
Tabela 1 - Levantamento geral de estudos sobre gênero

\begin{tabular}{lccc}
\hline Universidade & Gênero & $\begin{array}{c}\text { Gênero + } \\
\text { Educação Física }\end{array}$ & Crítérios de seleção* \\
\hline UFRGS & 1987 & 102 & 1 \\
UNICAMP & 847 & 43 & 2 \\
USP & 6069 & 39 & 1 \\
UNESP & 1541 & 24 & 0 \\
PUC & 748 & 2 & 5 \\
Total & 11192 & 210 & 1 \\
\hline
\end{tabular}

* Tese ou dissertação, ensino fundamental I; meninos e meninas; series iniciais; criança.

Cabe observar que nem todas as pesquisas encontradas a partir da palavra gênero referemse a forma como esse conceito é aqui utilizado . Desse modo, foi necessário delimitar mais a pesquisa combinando gênero com outras palavras chaves específico à temática desta pesquisa.

Assim, a pesquisa bibliográfica realizada das produções sobre gênero na Educação Física no ensino fundamental I localizou cinco teses e dissertações, que serão utilizadas neste estudo e estão representadas no quadro abaixo:

Quadro 1 - Dissertações e teses levantadas sobre gênero e Educação Física no ensino fundamental I

\begin{tabular}{|c|c|c|c|c|}
\hline Universidade & Autor (a) & Título & $\begin{array}{c}\text { Tipo de } \\
\text { produção }\end{array}$ & Ano \\
\hline UNICAMP & $\begin{array}{l}\text { PRESTA, } \\
\text { Michelle Guidi } \\
\text { Gargantini }\end{array}$ & $\begin{array}{l}\text { Atividades rítmicas na } \\
\text { Educação Física escolar: } \\
\text { relações de gênero, } \\
\text { preconceitos e possibilidades }\end{array}$ & Dissertação & 2006 \\
\hline UNICAMP & $\begin{array}{l}\text { FERNANDES, } \\
\text { Simone Cecília }\end{array}$ & $\begin{array}{l}\text { Os sentidos de gênero em } \\
\text { aulas de educação física }\end{array}$ & Dissertação & 2008 \\
\hline USP & $\begin{array}{l}\text { CRUZ, Tânia } \\
\text { Mara }\end{array}$ & $\begin{array}{l}\text { Meninas e meninos no } \\
\text { recreio: gênero, } \\
\text { sociabilidade e conflito }\end{array}$ & Tese & 2004 \\
\hline UFRGS & WENETZ, Ileana & $\begin{array}{l}\text { Gênero e sexualidade nas } \\
\text { brincadeiras do recreio }\end{array}$ & Dissertação & 2005 \\
\hline PUC & $\begin{array}{l}\text { PEREIRA, Fábio } \\
\text { Alves dos Santos }\end{array}$ & $\begin{array}{l}\text { Currículo, Educação Física e } \\
\text { diversidade de gênero }\end{array}$ & Dissertação & 2009 \\
\hline
\end{tabular}

Conexões: revista da Faculdade de Educação Física da UNICAMP, Campinas, v. 10, n. 3, p. 142-171, set./dez. 2012.148 ISSN: 1983-9030 
Nas pesquisas levantadas, realizamos um levantamento de quais temas são desenvolvidos a partir da temática de gênero nas aulas de educação física. Construímos a tabela abaixo onde serão demonstrados os temas tratados nas teses e dissertações sobre gênero no ensino fundamental I, e a partir dela realizaremos as análises. Desta forma, analisamos quais temas foram identificados em cada estudo marcando com um $\mathrm{X}$ e deixando em branco, quando o tema não foi identificado, porém alguns estudos apenas citam o tema e não desenvolvem uma análise direta e neste caso marcamos com $\checkmark$. Segue o Quadro abaixo:

Quadro 2 - Temas apresentados nas teses e dissertações sobre gênero e educação física no ensino fundamental I

\begin{tabular}{|c|c|c|c|c|c|}
\hline & $\begin{array}{l}\text { CRUZ } \\
\text { (2004) }\end{array}$ & $\begin{array}{c}\text { WENETZ } \\
\text { (2005) }\end{array}$ & $\begin{array}{l}\text { PRESTA } \\
\text { (2006) }\end{array}$ & $\begin{array}{l}\text { FERNANDES } \\
(2008)\end{array}$ & $\begin{array}{l}\text { PEREIRA } \\
\text { (2009) }\end{array}$ \\
\hline $\begin{array}{l}\text { Conteúdos da Educação } \\
\text { Física }\end{array}$ & $X$ & $X$ & $X$ & $X$ & $X$ \\
\hline $\begin{array}{l}\text { Habilidades corporais } \\
\text { relacionados a gênero }\end{array}$ & $X$ & $X$ & $X$ & $X$ & $X$ \\
\hline Futebol & $X$ & $X$ & $X$ & $X$ & $X$ \\
\hline Jogos e brincadeiras & $X$ & $X$ & $\mathrm{X}$ & $X$ & $X$ \\
\hline $\begin{array}{l}\text { Intervenção pedagógica } \\
\text { relacionada a gênero }\end{array}$ & $\checkmark$ & $\checkmark$ & $X$ & $X$ & $X$ \\
\hline Recreio & $X$ & $X$ & $\checkmark$ & $\checkmark$ & $\checkmark$ \\
\hline $\begin{array}{l}\text { Danças e atividades } \\
\text { rítmicas }\end{array}$ & & $\checkmark$ & $X$ & $X$ & $X$ \\
\hline Ginástica & & $\checkmark$ & $X$ & $X$ & $X$ \\
\hline Lutas & $X$ & $X$ & $\checkmark$ & & $X$ \\
\hline Vôlei & $\checkmark$ & $X$ & $\checkmark$ & & $X$ \\
\hline Basquete & & $\checkmark$ & $\checkmark$ & $\checkmark$ & $\checkmark$ \\
\hline Handebol & & & $\checkmark$ & & $\checkmark$ \\
\hline
\end{tabular}

Legenda: $[\mathrm{X}]$ = Identificado no estudo; [ ] = Não observado no estudo;

$[\checkmark]$ = Citado pelo estudo, sem ser objeto de análise direta. 
A observação desta tabela permite concluir que os principais temas abordados pelas pesquisas sobre gênero e Educação Física são: Conteúdos da Educação Física, Habilidades Corporais relacionadas a gênero, Futebol e Jogos e Brincadeiras. Todas as teses e dissertações sobre gênero aqui analisadas abordam tais temáticas.

Após a leitura dos textos selecionados, realizamos um fichamento dos mesmos e posteriormente sua resenha crítica. Dessa forma, os mesmos foram analisados a partir de três unidades de análise, a saber: "conteúdos e as relações de gênero", "diferenças nas habilidades corporais" e "relações de gênero: possibilidades de intervenção".

\section{CONTEÚdOS DA EDUCAÇÃO FÍSICA E AS RELAÇÕES DE GÊNERO}

Neste momento, analisaremos o que cada autor defende sobre as relações de gênero nos conteúdo da educação física, pautando-se no que os PCNs consideram como objeto de estudo da educação física, a cultura corporal de movimento, consistindo nas manifestações de esporte, lutas, jogos e brincadeiras, dança e ginástica. ${ }^{3}$

Diante dos resultados apresentados no Quadro 2, notamos que, em relação aos conteúdos da Educação Física todos os estudos tratam obre essa temática, e os conteúdos predominantes foram jogos e brincadeiras e futebol. Ginásticas, Lutas e Dança e atividades rítmicas aparecem em apenas três pesquisas de maneira mais aprofundada e um estudo apenas citou, não especificando o tema. Já vôlei, basquete e handebol foram citadas em uma quantidade inferior de pesquisas.

Wenetz ${ }^{8}$ e $\mathrm{Cruz}^{10}$ realizaram suas observações no recreio, e alegam que neste momento as crianças estão mais relaxadas e soltas, distantes do controle dos adultos, e a partir das observações essas descrevem as práticas realizadas no recreio por meninos e meninas. Diante destas descrições faremos análises e comparações com os conteúdos da educação física.

Nota-se que no recreio e nas aulas de Educação Física, meninas e meninos participam juntos apenas de atividades desprovidas de significados de gênero como jogos e brincadeiras de perseguição ou jogos criados por eles mesmos, como se esses jogos fossem Conexões: revista da Faculdade de Educação Física da UNICAMP, Campinas, v. 10, n. 3, p. 142-171, set./dez. 2012. 150 ISSN: 1983-9030 
permitidos por não possuírem estereótipos que condicionam a sua pratica, o que não acontece com o futebol em que apenas meninos foram observados jogando e no caso da dança praticada apenas pelas meninas.

De acordo com as teses e dissertações o pega-pega é uma preferência lúdica das alunas e alunos e, como foi observado é uma atividade em que meninos e meninas praticam juntos no recreio, onde estão distantes dos adultos, seja com conflito ou não, rompem com as barreiras de gênero e manifestam a necessidade dos mesmos de conviverem juntos, e ainda revelando-se como algo prazeroso.

O interesse e motivação para a prática de alguma manifestação corporal pode ser afetado pela dificuldade do aluno ou aluna em realizá-la, muitas vezes essa inabilidade é justificada por discursos biologista como inata ao sexo, mas isso ocorre pela falta de vivências em determinada prática corporal.

Assim como Presta ${ }^{22}$ observou na atividade de corda, que o interesse prevaleceu na maioria das meninas e a dificuldade de realizar a atividade afetou o interesse de alguns meninos, mas isso é explicado não pela incapacidade biológica do sexo e sim por restrição a vivência nesta atividade, assim como acontece com as meninas nos jogos coletivos, principalmente o futebol. Além disso, o autor acredita que além da atividade com corda ter uma característica cultural feminina, alguns meninos se cobravam em ter obrigação de sucesso na atividade. Pois pela maioria dos meninos serem mais incentivados a "jogar bola”, e por terem na maioria das vezes sucesso, quando a atividade muda, eles buscam o mesmo sucesso, só que de forma imediata, sem se familiarizar com a atividade, e como não conseguem o mesmo desempenho desanimam em realizar atividade, dizendo muitas vezes que não gostam, só porque não conseguem fazer. Com isso o autor percebeu que deveria ter sugerido uma brincadeira que trabalhasse a mesma dinâmica da corda, a mesma habilidade de saltar, mas que estivesse em outro contexto, para assim os meninos se sentirem mais motivados e desafiados a participar, e essa situação também pode ocorrer com as meninas, como no caso do futebol.

Neste contexto, podemos entender que o trabalho com atividades generificadas, seja com corda, com o futebol, danças dentre outros, deve-se ter um cuidado maior no planejamento 
das atividades, para que não ocorra o desinteresse dos/as alunos/as, reafirmando e reproduzindo estereótipos de gênero em torno das práticas corporais. Torna-se necessário no ensino das atividades generificadas uma adaptação, no sentido de colocar o foco principal da atividade como algo secundário para não enfatizar o erro. Esses princípios devem ser incorporados na prática pedagógica do/a professor/a e quanto antes forem trabalhados com os/as alunos/as, menos estereótipos e resistências quanto à prática serão gerados.

Assim como Fernandes ${ }^{19}$ observou em seu estudo, que essa associação entre práticas corporais e gênero não é manifestada nas duas primeiras séries escolares, exceto esse gosto pelo futebol, pelo fato de muitos alunos e poucas alunas já iniciarem a prática exterior a escola. E as demais práticas corporais as crianças irão aprender, sendo possível construir um conhecimento livre de estereótipos.

Sobre a construção desses estereótipos em torno da prática, Presta $^{22}$ afirma que nos esportes, como o futebol, basquete e vôlei e outros, cuja organização oficial está baseada na separação de homens e mulheres, os meninos e as meninas não sentem vontade de competir entre si, preferem realizar as atividades separados, o que não ocorre em jogos não oficiais como a queimada, por exemplo, eles não se importam em jogar junto. Quando há a manifestação de jogarem separados, a queixa das meninas é que os meninos são brutos e os meninos dizem que elas são "lerdas" para acompanhá-los. Nesta escola, meninas e meninos sempre tiveram aulas juntos, o autor acredita que essa cultura de aulas separadas possa vir dos pais que provavelmente, no período escolar, tiveram aulas separadas, o que pode não contribuir para a co-educação. Consequentemente, “os meninos não aprendem a respeitar os limites das meninas e dos alunos menos habilidosos e as meninas continuam a se julgar incapazes e inaptas a praticar esporte". 22: 59

Wenetz ${ }^{8}$ citando Altmann ${ }^{23}$ e Gonçalves ${ }^{24}$ afirma que os meninos através de sua habilidade técnica do saber jogar futebol, impõem-se no espaço (a quadra) e também no tempo do recreio. Cruz ${ }^{10}$ corrobora com essa afirmação e confirma que em seu estudo o futebol era um forte indicador de identidade coletiva que unia os meninos entre si e através desses dominavam o espaço do recreio. 
Um fato muito interessante sobre a manifestação das meninas contra o domínio da quadra por meninos com a prática do futebol ocorreu no estudo de Cruz. ${ }^{10} \mathrm{~A}$ autora presenciou, através de uma discussão acirrada das meninas de uma $3^{\mathrm{a}}$ série, no qual argumentavam a injustiça do domínio do futebol e contaram com o apoio incisivo de muitos meninos a favor de um uso mais aberto da quadra poliesportiva. Reflexo da configuração de gênero ali encontrada, as propostas incluíam um revezamento baseado em um leque variado de opções, como por exemplo, a decisão provisória de na quarta-feira, jogar vôlei e queimada mista, na quadra poliesportiva e na sexta-feira, jogar futebol misto no campinho. O futebol neste contexto representava intensas disputas de poder e de espaço nas relações de gênero e na maioria das vezes favorável aos meninos.

A dança e o futebol foram o foco da pesquisa Pereira ${ }^{11}$ justamente por esses conteúdos manifestarem preconceitos e discriminações nas aulas de educação física, pelo fato da dança ser construída culturalmente como atividade generificada a prática das meninas e futebol a prática dos meninos.

Contudo, podemos observar que as manifestações corporais estão arraigadas de estereótipos socialmente construídos, o que acaba por limitar a vivência de alunos e alunas, condicionados a ter interesse por determinada prática corporal devido a características ligadas a papéis sexuais impostos pela sociedade, descartando e influenciando a vontade própria da aluna ou aluno. E muitas vezes por falta de vivência, apresentam dificuldade o que afeta o seu interesse e assim não possuem uma "verdadeira oportunidade" para optar por qual manifestação deseja praticar. Desta forma é preciso ressignificar e problematizar com os alunos e alunas tais manifestações corporais, para que possam compreender e analisar criticamente o que está implícito no contexto de sua prática.

Buscando esta compreensão dos/as alunos/as em torno do futebol, Pereira ${ }^{11}$ realiza um resgate histórico sobre ele, e contextualiza inclusive sobre o inicio da participação das mulheres no mesmo, mostrando que estas tiveram muita dificuldade para jogar futebol, pois foram até mesmo proibidas por um decreto lei de praticá-lo, e além da proibição legal, discursos biologistas afirmavam que o futebol, por ser violento, poderia afetar os órgãos reprodutores femininos, chegando a lesões mamárias e elas teriam pernas, joelhos e tornozelos mais grossos, perdendo as características femininas. Diante desses fatos 
geraram-se relações de desigualdades construídas socialmente e consequentemente o futebol feminino só foi legalizado em 1979. Hoje graças a muitos esforços pioneiros, ele é mais praticado e aceito socialmente, mas está longe de se alcançar o ideal, até mesmo porque as meninas ainda sofrem discriminações, principalmente na escola, e essa não está aproveitando as permissões da sociedade e problematizando as relações de desigualdades socialmente construídas.

A partir deste resgate histórico, Pereira ${ }^{11}$ entende que o futebol é o esporte mais popular no Brasil, o que reflete nas preferências dos alunos nas aulas de educação física. No entanto, pelo fato do futebol ter sido criado, modificado e dirigido por homens, ele possui todas as características atribuídas ao masculino, que são elas: o jogo deve ser violento, chutes fortes, jogadas firmes, muitas faltas, contato físico inevitável e a vitória acima de tudo, sendo considerado um "esporte para homem”. E é esse mesmo futebol que geralmente é praticado nas escolas. Todavia, as aulas de Educação Física devem contribuir para a formação global do cidadão, pois se pautando em Darido, ${ }^{25}$ Pereira ${ }^{11}$ acredita ser este é um espaço em que educandas e educandos devem ter as mesmas oportunidades de aprendizagem, com construção de significados éticos e constitutivos da ação de cidadania, necessários para colocar-se contra valores e práticas sociais que desrespeitem a dignidade humana, promovendo assim discussões sobre a igualdade de direitos, recusa de formas de discriminação e importância da solidariedade. Na busca para atender a essas necessidades o autor utiliza-se do diálogo com alunas e alunos para conscientizá-los destes princípios educacionais.

Conforme Fernandes, ${ }^{19}$ o futebol e as articulações de gênero podem aumentar as dificuldades de aprendizagens e o distanciamento entre meninos e meninas, pois os meninos que sabem jogar, não estão abertos para aprender e se colocam como competidordemonstrador já quem não sabe jogar não se empenha para aprender e é desestimulado com as constantes informações.

A visão da Educação Física sofreu influências do tecnicismo e esportivismo, com turmas divididas por sexo, e as mulheres restavam à prática do voleibol, dança e ginástica, pois esportes violentos e de contato eram contra-indicados. Souza e Altmann ${ }^{4}$ explicam que com a introdução do esporte moderno como conteúdo da Educação Física escolar no 
Brasil, a mulher considerada pela sua "natureza" dócil, sentimental e seu corpo frágil era considerada vencedora nas danças e artes, sendo permitida também a prática de voleibol e ginástica rítmica, pela suavidade de movimentos e a distância entre os corpos. Por essas características serem negadas a "natureza" do homem, a ele era permitido praticar futebol, basquete e judô, por serem esportes violentos e viris, pois exigiam esforços, confronto corpo a corpo e movimentos violentos, contribuindo para a formação da masculinidade. Caso eles utilizassem as práticas corporais permitidas às mulheres eles correriam o risco de serem visto pela sociedade como efeminados, e vice e versa com as mulheres, só que poderiam masculinizá-las.

Ilustrando e corroborando com a afirmação acima, Pereira ${ }^{11}$ descreve sua experiência pessoal nas aulas de educação física, no qual gostava muito de jogar vôlei porque tinha muita facilidade e ao contrário dos meninos de sua sala não gostava de jogar futebol e era discriminado por isso, onde seus colegas de classe o chamavam de "bichinha", "veadinho". Chegou um momento de sua vida que mesmo gostando muito de vôlei ele desistiu de jogar, para não ser mais "bichinha" e continuou jogando futebol, mesmo sendo escolhido por ultimo ou as vezes nem sendo escolhido, tudo porque o futebol era considerado por seus colegas esporte de homem.

Segundo Wenetz ${ }^{8}$ o tipo de brincadeira e as pessoas com quem brinca parece determinar a classificação quanto a ser ou não "bicha" para as crianças, sendo que se um menino brincar de alguma brincadeira considerada de menina, isso será o suficiente para chamá-lo de "bicha”, porém quando questionadas se existem ou não brincadeiras só de meninas ou só de meninos, surgem algumas dificuldades e contradições. Embora, algumas crianças que já vivenciram bricandeiras do outro gênero, ou seja, quando um menino pula corda ou uma menina joga futebol, esses possuem dificuldades para classificar a brincadeira como de um só gênero, o que acaba por desconstruir a idéia de que as brincadeiras por si sós estabelecem quem deve brincar, "todos brincam", de acordo com uma aluna estrevistada. Talvez esses estereótipos construídos historicamente nas aulas de Educação Física possam ser explicados se recorrermos à história da educação física, se analisarmos a sua introdução no currículo das escolas brasileiras. 
Corroborando com essa idéia Pereira ${ }^{11}$ afirma que o início da Educação Física na escola esteve ligada ao militarismo e a concepções higienistas, sendo vista como responsável pela formação de um povo forte e saudável, prevenindo os problemas de saúde publica, e para atender esse objetivo foi instituída por Rui Barbosa a ginástica para ambos os sexos, porem com atividades diferenciadas. Construindo estereótipos idealizados para os corpos femininos e masculinos. Porém, nesta proposta diferenciada os homens foram privilegiados, por receberem mais possibilidades para se desenvolverem corporalmente.

Atualmente, verificamos que ainda há esportes praticados apenas por um determinado sexo como é o caso da ginástica rítmica ou nado sincronizado, que apenas mulheres podem competir, ou no caso do Sumô no Japão, onde só homens podem lutar e a mulher é até mesmo proibida de entrar no Dojô (local onde ocorre a luta). Neste caso verificamos a discriminação de gênero em que um ser homem ou um ser mulher é proibido de fazer ou ter algo, apenas porque pertence a determinado gênero. ${ }^{11}$

Também há esportes que são praticados por ambos os sexos de maneiras diferenciadas, como a Ginástica artística e algumas provas do Atletismo, ou no Vôlei em que a rede possui tamanho diferenciado, para os homens a rede mede $2,43 \mathrm{~m}$ de altura, e para as mulheres $2,24 \mathrm{~m} .^{11}$

Em relação a exclusividade das mulheres em competições de Ginástica Rítmica e Nado Sincronizado, Pereira ${ }^{11}$ acredita que isso ocorra por essas atividades exigirem características historicamente atribuídas as mulheres, como a leveza, beleza, graça e destreza nos movimentos.

Pereira ${ }^{11}$ concordando com Sousa e Altmann ${ }^{4}$ se coloca contra este monopólio feminino na Ginástica Rítmica, pois a experiência nesta ginástica possibilitaria uma vivência significativa para ambos os sexos, por proporcionar a interação do corpo com o manejo de aparelhos diversificados. E ainda, Pereira ${ }^{11}$ acredita que essa vivência proporcionaria uma percepção sobre as diferenças de gênero, e as/os alunos/as teriam consciência de que os estereótipos não são exatamente quanto aparentam ser, nada mais é que uma ideologia, e há varias formas de ser meninos e meninas, contudo mesmo em uma cultura machista, nem todos os meninos são agressivos e nem todas a meninas são frágeis. Há meninas que gostam de futebol e há meninos que gostam de dança. 
Fernandes ${ }^{19}$ descreve uma situação em que levou para aula 30 fitas de Ginástica Rítmica Desportiva para as crianças da primeira série, elas realizaram movimentos ensinados por ela e apresentaram, ao final da aula, coreografias com movimentos, rolamentos, giros, saltos e canções. Notou que quando estimuladas e ensinadas, as crianças se empenham em aprender tudo, "desconstruindo ou afirmando esses gostos primeiros". Desta forma a autora, verificou que o aparelho fita da ginástica despertou interesse de manuseio em todas as crianças, embora alguns meninos considerassem como "isso é coisa de menina!", logo depois, cederam a novidade. Contudo a autora alerta ser "interessante polemizar com as crianças esses sentidos que se atrelam entre práticas corporais e gênero que limitam as possibilidades de descobrirem os conhecimentos que a escola tem para ensiná-las”.

Presta $^{22}$ utilizou-se da Ginástica Geral para romper as barreiras do preconceito de que ginástica é “coisa de menina”, e como esta prática possui um número expressivo de homens, foi uma estratégia que utilizou para motivar os meninos a fazer a ginástica.

Ao ensinar dança na escola, para Pereira ${ }^{11}$ é preciso considerar as imagens que alunas e alunos têm sobre a dança, bem como os preconceitos, trabalhando para superá-los, buscando questionar, problematizar e desconstruir os estereótipos atribuídos ao dançar das meninas e meninos. "Todavia, essa desconstrução não significa negar às meninas a dança e obrigar os meninos a dançarem. A dança pode ser oferecida a todos aqueles que quiserem dançar, e as escolhas devem ser individuais, prevalecendo, sobretudo, o respeito às diferenças". 11

Segundo Presta ${ }^{22}$ desenvolver um trabalho em torno das relações de gênero com as/os alunas/os nas séries iniciais pode ajudá-las/los a aceitar e a entender a importância desses processos. "É necessário, embora não suficiente, começar cedo, e ensinar dança de uma forma agradável para os meninos e que uma maneira que não seja ameaçadora de sua masculinidade". 26: 68; 22

Assim é preciso ressignificar alguns preconceitos existente na dança como por exemplo o ato de rebolar, onde Pereira ${ }^{11}$ utiliza Houaiss ${ }^{27}$ para conceituar o rebolar como sendo o ato de mover-se como uma bola, rolar ou andar balançando o quadril. Para Pereira ${ }^{11}$ rebolar também é o nome dado para o movimento do quadril quando surgiu o "modismo" do 
bambolê, e que por ser um implemento da ginástica rítmica desportiva que só as mulheres praticam, foi popularizado de modo preconceituoso como um movimento feminino e muito explorado midiaticamente em programas televisivos. Entretanto, o movimento em si não tem nada de exclusivamente feminino ou masculino, mas sim, de humano, é um movimento como qualquer outro.

$\mathrm{Kunz}^{28}$ citado por Pereira ${ }^{11}$ afirma que através da dança o homem pode vivenciar os benefícios emocionais, que ainda é um privilegio feminino, possibilitando a liberdade para cada um dançar da sua maneira, sem associação com modelos e padrões históricos das formas de se movimentar, respeitando o interesse, individualidade, feminilidade e masculinidade do ser humano.

Assim como no futebol, Pereira ${ }^{11}$ defende um ensino de dança através do diálogo com as/os alunas/os, valorizando o que eles conhecem sobre o tema e conscientizando-os sobre estereótipos e preconceitos em torno da dança, também é preciso que o/a professor/a dê exemplo e mostre que esses preconceitos não possuem fundamentos sólidos.

Um ponto muito importante levantado por Presta $^{22}$ é como as escolas de educação infantil reforçam os estereótipos existentes na sociedade, ao utilizar como atrativo e diferencial da escola, atividades distintas para as crianças: aulas de balé clássico para as meninas e judô para os meninos. Dessa maneira, as crianças desde cedo têm experiências corporais distintas. O que é intrigante é que os cursos de inglês, espanhol, natação e computação são oferecidas para todos os/as alunos/as indistintamente, enquanto que a dança é exclusivo para as meninas e o judô para os meninos. Observa-se que é justamente no corpo que as diferenças de gênero são marcadas. As instituições de ensino deixam de cumprir sua responsabilidade impulsionar transformações e ser espelho para quebrar preconceitos, buscando formar para a cidadania e não para reprodução de preconceitos.

Nota-se que as lutas através do judô são oferecidas na educação infantil e acabam por gerar estereótipos. No entanto pouco se fala desse conteúdo nas aulas de Educação Física das séries iniciais, como foi demonstrado no Quadro 2, três autores trataram desse conteúdo e apenas um cita, no entanto, ginástica e dança tiveram a mesma quantidade, porém foram tratados como mais profundidade. 
$\mathrm{Cruz}^{10}$ é citada por todos os autores que se referiram as lutas, trata mais profundamente deste conteúdo. Para a autora as lutinhas correspondiam à maneira que os meninos usavam para interagir no recreio, sendo comum observá-los em pequenos grupos simulando socos e chutes, disputas de forças, atividades cheias de ludicidade e diversão para os meninos.

Neste contexto estão presentes as características que fazem parte do aprendizado das lutinhas, apresentadas por Olivier ${ }^{29}$ que podem ser desenvolvidas através de jogos de lutas correspondendo a jogos de oposição, dentro da classificação de jogos de lutas apresentada pelo autor. Nos jogos de oposição o participante deve controlar as ações do adversário, observando-o, brincando de opor-se e ao mesmo tempo encontrando-o, reconhecendo-o e respeitando-o como "adversário-parceiro", envolvendo aspectos sócio-afetivos ao se colocarem corpo a corpo.

As meninas também contribuem de diversas maneiras para a construção desta masculinidade associada a força, a capacidade de autodefesa e resistência a dor, pois os meninos atribuem a elas o papel de juízas para observar e avaliar a brincadeira. As lutinhas estavam tão presentes nas observações de Cruz ${ }^{10}$ ao contexto escolar, que essas influenciavam a concepção de masculinidade e feminilidade das meninas e adultos da escola.

As meninas não possuem um jogo como a lutinha no qual se construa identidade sexual de poder e dominação, assim as culturas colocam a disposição das crianças, particularmente os meninos, um conjunto de símbolos e experiências de masculinidade no qual os jogos de lutas estão no centro e serão determinantes na construção da identidade masculina. As experiências lúdicas diferenciadas desde os primeiros anos dos meninos influenciarão o modo de lidar com os demais jogos, sendo parte de um aprendizado prévio de uma dimensão física e agressiva de jogar, que envolve a competição e a força.

Mas porque meninas não podem vivenciar atividades de lutas nas aulas de educação física? As lutas podem contribuir para a formação da identidade das alunas, onde elas poderão conhecer e respeitar seus limites e do outro e inclusive dos meninos, e há diversas formas de lutar, aquelas que envolvem mais força, outras equilíbrio, agilidade, dentre outras habilidades, proporcionando a vivencia de experiências diversificadas. Tornando possível 
que as alunas conheçam esse patrimônio cultural da humanidade, valorizando e ressignificando conhecimentos fidedignos a sua prática.

Diante das discussões e análises deste capítulo podemos entender que a Educação Física desde sua introdução no currículo da educação brasileira, sofre influências de uma sociedade preconceituosa e discriminadora na construção de estereótipos em torno de seus conteúdos, bem como também reproduz e gera estereótipos em torno das relações de gênero, que acabam por prejudicar e dificultar o processo de ensino- aprendizagem e desenvolvimento tanto de meninas como de meninos, que são limitados e condicionados a prática de manifestações corporais determinadas pelos papéis sexuais socialmente aceitos, reflexos de um discurso biologista, que desconsidera a individualidade de cada ser humano e as manifestações de seus desejos e necessidades.

Os conteúdos da Educação Física como esporte e lutas tiveram historicamente características como força, agressividade atribuídas à masculinidade, estimulada nos meninos, e a dança e a ginástica, características ligadas emoção e delicadeza atribuídas a feminilidade, incentivada nas meninas, como se a prática dessas manifestações corporais pudessem determinar a orientação sexual de meninos e meninas. Esses conteúdos são independentes das conotações sexuais, e devem ser vivenciados por ambos os sexos, trazendo contribuições para a formação integral de meninos e meninas. Se a Educação Física no passado se omitiu em torno das relações de gênero, utilizando as diferenças sexuais para justificar submissão de uns em detrimento de outros, que no presente ela reconheça e valorize as diferenças e que essas não sejam motivo para cerceamento do desenvolvimento de meninas e meninos, que sejam problematizadas e ressiginificadas e que no futuro a Educação Física contribua para a transformação social garantindo uma formação comprometida com a cidadania.

\section{AS DIFERENTES HABILIDADES CORPORAIS}

Ao analisarmos o Quadro 2 desta pesquisa verificamos que todos os estudos tratam da relação das habilidades corporais e gênero. Talvez, por ser esta uma das razões utilizadas por muitos para justificar as desigualdades de gênero, e assim, sendo de fundamental importância a sua compreensão para que as diferenças sexuais não justifiquem a submissão de uns em detrimento de outros.

Conexões: revista da Faculdade de Educação Física da UNICAMP, Campinas, v. 10, n. 3, p. 142-171, set./dez. 2012. 160 ISSN: 1983-9030 
Romero $^{30}$ entende que há diferença em relação a experiências de movimentos vivenciados por meninos e meninas. Os meninos autorizados e estimulados a realizarem brincadeiras mais livres e mais agressivas, tais como: jogar bola nas ruas, soltar pipas, andar de bicicleta, rolar no chão em brigas, escalar muros e muitas outras atividades com riscos e desafios. Já as meninas são desestimuladas e, até mesmo impedidas, de realizar essas brincadeiras e atividades e, e por causa desse tratamento diferenciado, encontramos um quadro de desempenho motor igualmente diferenciado. O que pode resultar numa maior dificuldade motora, entre as mulheres principalmente, para a prática de alguns esportes.

Daólio $^{31}$ não deseja igualar homens e mulheres em relação ao uso do corpo, mas sim acredita que inicialmente, devemos "compreender que as diferenças motoras entre meninos e meninas são, em grande parte, construídas culturalmente, e, portanto, não são naturais, no sentido de serem determinadas biologicamente e conseqüentemente irreversíveis".

Connell $^{32}$ citado por Sousa e Altmann ${ }^{4}$ defende que se os corpos adquirem a organização social, a política e as normas religiosas e culturais, também é por sua intervenção que se manifestam as estruturas sociais. Assim, há uma estreita e contínua sobreposição entre o social e o biológico, "um jeito de ser masculino e um jeito de ser feminino, com atitudes e movimentos corporais socialmente entendidos como naturais de cada sexo". As autoras acreditam que, o processo de educação de homens e mulheres presume uma construção social e corporal dos sujeitos, o que envolve conhecimentos, posturas e movimentos corporais compreendidos como masculinos ou femininos.

Segundo Fernandes ${ }^{29}$ o fato dos meninos jogarem futebol era percebido, por muitos, "como um marco de gênero exaltado e não como uma diferença em suas aprendizagens corporais". Ou seja, os meninos sabiam jogar futebol porque eram meninos e as meninas não jogavam bem porque eram meninas. Mas, segundo a autora eles desde quando nascem são estimulados a gostar e a aprender esse esporte o que não ocorre com elas, que são na grande parte das vezes estimuladas a outros tipos de atividades (individuais e manuais). Fernandes ${ }^{19}$ relata ainda que os meninos são mais estimulados, desde a pré-escola, a participarem de jogos coletivos, e isso facilita a prática deles mediante os conteúdos da educação física, diferentemente das meninas. 
Concordamos com a autora quando esta diz que nós como professores/as devemos vislumbrar uma prática docente na qual meninos ou meninas, possam aprender nas aulas, a partir da mediação entre os, saberes que cada criança possui e o conhecimento da educação física. ${ }^{19}$ Entendemos que, o importante é que cada criança, independente de suas vivencias prévias, possam nas aulas de Educação Física experimentar as variadas experiências que os conteúdos da Educação Física escolar propicia. Daólio ${ }^{33}$ afirma ser importante respeitar as diferenças e ao mesmo tempo proporcionar às crianças as mesmas oportunidades de aprender.

Para Fernandes, ${ }^{19}$ aos professores/as requer-se o reconhecimento de que as crianças são diferentes, e isso faz das aulas de Educação Física uma expressão da diversidade entre elas, permitindo a todas conhecer e ampliar as possibilidades de estar e mudar o mundo ao seu redor por meio da cultura corporal. Ainda para esta autora, as estratégias de ensino podem ser diferenciadas. Não se trata de separar "meninas de um lado e meninos de outro", como ocorre com frequência nas escolas, mas de usar como critério de divisão da turma o saber incorporado pelas crianças, ressaltando a separação como uma necessidade pedagógica e, gradualmente, ir possibilitando e ensinando as crianças a ter aulas conjuntas, com aprendizagens diferenciadas.

Fernandes ${ }^{19}$ diz que $a$ "predominância dos esportes nas aulas de Educação Física também contém significados de gênero que precisam ser polemizados". Para a autora se os esportes estiverem vinculados a um sentido masculino em nossa sociedade, possibilitar a expressão de outras gestualidades corporais é uma maneira de democratizar o espaço da aula de Educação Física e contemplar outros arranjos de gênero.

Presta $^{22}$ diz que as características biológicas ainda são fortemente utilizadas para embasar os discursos que permeiam as discussões de gênero, bem como a justificativa para as diferenças comportamentais e desigualdades sociais entre homens e mulheres.

Segundo Cruz, ${ }^{10}$ maior do que a consciência de assumir-se como masculino ou feminino,será a relação do indivíduo com seu próprio corpo e com os outros corpos, constituída a partir das relações de gênero como tensões, posturas e habilidades físicas. 
Podemos estranhar certas articulações que perpassam a educação física: quais são as normas de inteligibilidade corporal que circundam o imaginário desta disciplina? Corpos masculinos associados à força física e agilidade; corpos femininos vinculados a gestos mais graciosos? Podemos afirmar que existe uma norma do tipo: corpo negro, alto, ágil e rápido $=$ interesse esportivo pelo basquetebol? Mas sabemos que nem todas as pessoas com esses corpos se interessarão por esse esporte, e que todas/os alunas/os, independentemente se são homens ou mulheres, negras ou brancas, altas ou baixas, gordas ou magras, rápidas ou lentas... têm os mesmos direitos de realizar as aulas na escola. ${ }^{19}$

Fernandes ${ }^{19}$ defende a necessidade de ir além das perguntas "dicotomizadas" que apontam um binarismo rígido nas relações de gênero, caminhando para um olhar que contemple as múltiplas e complexas combinações de gênero que estão presentes em todos os arranjos escolares.

É preciso estranhar as diferentes habilidades corporais com a certeza de que não são da ordem da natureza e com a mesma convicção de que as meninas e os meninos são capazes de aprender . Então além de diversificar os conteúdos torna-se latente ressignifica-lós a fim de facilitar, autorizar, permitir que ambos, meninos e meninas possam realizar as aulas e por em prática suas hipóteses de movimentos.

\section{"PROPOSTAS DE INTERVENÇÃO" - AS RELAÇÕES DE GÊNERO E AS POSSIBILIDADES DE INTERVENÇÕES}

Os resultados observados na Tabela 1 , como já mencionados anteriormente, demonstram a necessidade de promoção de pesquisas sobre essa temática, o que parece afetar a possibilidade de subsídios teóricos e práticos para fundamentar a intervenção pedagógica das/os professoras/es da educação básica, como apresentado no Quadro 2, em que apenas três estudos se preocupam em proporcionar instrumentos pedagógicos para o trabalho com gênero nas aulas.

Buscamos analisar os estudos de Pereira, ${ }^{11}$ Presta $^{22}$ e Fernandes, ${ }^{19}$ unidos a outros estudos sobre as relações de gênero para fornecer elementos e estratégias de ensino como possibilidades de intervenção pedagógica no trato de gênero nas séries iniciais. 
Para Fernandes ${ }^{19}$ as estratégias de ensino de meninos e meninas podem ser diferenciadas. Segundo a autora não se trata de separar "meninas de um lado e meninos de outro", como ocorre comumente nas escolas, mas de usar como critério de divisão da turma o saber incorporado pelas crianças, ressaltando a separação como uma necessidade pedagógica e, gradualmente, ir possibilitando e ensinando as crianças a ter aulas conjuntas, com aprendizagens diferenciadas.

Ainda segundo Fernandes ${ }^{19}$ trabalhar com grupos considerando as diferenças de aprendizagem corporal pode permitir criar uma aula com a qual as crianças não sintam vergonha em demonstrar que não sabem fazer o que foi proposto, porque nos grupos estarão outras crianças com semelhantes dificuldades. E porque, em se tratando de futebol, as crianças que sabem desejam muito jogá-lo, sendo difícil, para estas crianças, aulas conjuntas com o propósito de elas ajudarem a ensinar as crianças que não sabem. A exclusão neste caso é encarada como exclusivamente de gênero, como se apenas as meninas enfrentassem esse problema, sendo desconsideradas outras formas de exclusão às quais a de gênero está acoplada. Priva-se, assim, outros excluídos dos possíveis benefícios gerados a partir da intervenção. ${ }^{23}$

Segundo Fernandes ${ }^{19}$ é interessante o/a professor/a de Educação Física discutir em suas aulas a idéia de "isso é coisa de menino/a!" através de imagens, leituras, brincadeiras, proporcionando discussões com as/os alunas/os sobre estas questões.

Outra estratégia citada por Fernandes ${ }^{19}$ seria a de criar situações inusitadas, que não contêm imagens generificadas. Isto também, segundo ela, auxiliaria a romper com os sentidos binários tal como fizemos ao solicitar três filas durante uma aula com corda.

Para Presta, ${ }^{22}$ as/os professoras/es podem se utilizar de discussões em suas aulas sobre os papéis sexuais a fim de pensar formas de ação que possam contribuir para vivências não discriminatórias. Ressalta que, na maioria das aulas de Educação Física do ensino fundamental I, as aulas são mistas, porém diz que mais importante de se juntar meninos e meninas é pensar como o trabalho pode ser desenvolvido a fim de não continuar priorizando atividades para os meninos e atividades para as meninas. 
Outra sugestão de Presta, ${ }^{22}$ na hora da classe realizar uma roda de conversa seria aconselhável pedir para as/os alunas/os se sentarem ao lado de um colega ao qual conversa pouco e não exigir que devam sentar intercalando menina e menino, pois assim, a autora acha que se estaria fechando as possibilidades de escolha e determinando como deve ser feito. Propor movimentos fortes, músicas marcantes com instrumentos de percussão e modificar os nomes das atividades podem ser uma forma de dar preferência somente àquilo que os meninos aceitam fazer.

Darido $^{25}$ cita algumas estratégias de contextualização da questão de gênero nas aulas de Educação Física escolar, como a utilização da mídia para discutir sobre preconceito e sexismo, procedimentos que envolvam todos e adaptações e alterações de regras.

Faria Junior ${ }^{34}$ enfoca o desenvolvimento das competências relacionais e individuais, entendendo que o futebol como desporto de equipe, pode atuar como meio eficaz de ensinar aos jovens a tolerância e aceitação das diferenças individuais e para isto propõe uma série de procedimentos das/os professoras/es de Educação Física.

Alguns autores relativizam a validade das adaptações de regras dos jogos. Altmann ${ }^{23}$ levanta alguns contra argumentos com relação às mudanças das regras para facilitar a participação das garotas. Dizendo que ao criar regras específicas que possibilitam uma maior participação feminina no jogo, condiciona-se o gol ao toque de todos os jogadores ou autorizava-se apenas às meninas a marcá-los. Essas regras, ao impedirem que um jogador livre de marcação marque um gol, quebram a dinâmica do jogo, e as meninas podem ser "culpadas" por isso, pois fora por causa delas que as regras haviam sido modificadas.

Altmann $^{23}$ afirma que para além de uma exclusão de gênero, há nos esportes uma exclusão por habilidades. Desta maneira, a fim de garantir o acesso de todas as crianças às práticas esportivas, uma possível estratégia, em especial, no ensino do futebol pode ser separar, durante alguns momentos ou algumas aulas, meninos e meninas que sabem daquelas e daqueles que não sabem, com o objetivo de possibilitar o acesso de todas as crianças a esse elemento da cultura brasileira. 
$\mathrm{Na}$ Espanha, com o objetivo de aumentar e promover a igualdade de participação das meninas na Educação Física escolar e na prática de atividades físico-desportiva e romper com os estereótipos de gênero existentes foi implantado no ano de 2010, uma proposta pedagógica para o ensino primário e secundário, focada no $5^{\circ}$ e $6^{\circ}$ ano, chamada "Guia PAFIC - para a promoção da atividade física em meninas", sendo esta uma alternativa encontrada pelo governo espanhol para diminuir os estereótipos de gênero na escola, envolvendo também a comunidade. O Guia PAFIC possui como áreas de atuação: Área curricular de Educação física escolar; Atividade físico-desportiva extracurricular; Ambiente escolar ; Ambiente familiar; Relação escola-comunidade. Dentro dos cinco âmbitos, as ações são estruturadas da seguinte forma:- objetivo; - estratégia; planejamento de intervenção; - atividades. Abaixo serão expostos alguns exemplos de aula referente a área de educação fisica. ${ }^{35}$

Através das considerações apresentadas reconstruímos algumas cenas comuns nas aulas de Educação Física: de modo geral, aos nossos conteúdos clássicos perpassam informações de gênero que facilitam/dificultam a prática de meninas e meninos na escola. $\mathrm{O}$ esforço em problematizar essas ligações "sexo/prática corporal" percorre todo o trabalho, de modo central, buscamos uma ação educativa igualitária e libertária quanto aos estereótipos.

No entanto, há um descompasso entre o discurso e o cotidiano das aulas, os quais ainda reproduzem desigualdades de gênero. Desta forma, ao longo do trabalho buscaram-se princípios para nortear as aulas de Educação Física, porém precisam ser sempre diariamente - informados e reafirmados pelos professores e professoras. Se muitos préconceitos constantemente reafirmados são inconscientes é preciso tomar consciência por meio da formação em "estudos de gênero na escola". Mas isso talvez deva ser atribuído aos adultos imersos nessas teias de significados.

\section{CONSIDERAÇÕES FINAIS}

Esta pesquisa investigou a produção acadêmica sobre as relações de gênero no ensino fundamental I. A partir da análise de teses e dissertações disponíveis nas bibliotecas de algumas das principais universidades do País. Embora os estudos de gênero sejam uma área de pesquisa consagrada no Brasil, as pesquisas sobre Ensino Fundamental I ainda são em pequeno número. 
Podemos observar que as desigualdades nas relações de gênero estão presentes em praticamente todos os conteúdos da educação física, ora privilegiando os meninos ora as meninas. Os conteúdos de jogos e esportes, especificamente o futebol foram aprofundados e discutidos por todos os autores analisados, porém notamos carência de produção de conhecimento em relação as danças, lutas, ginásticas e esportes que não sejam o futebol.

Outro aspecto fundamental é em relação à intervenção pedagógica. Os argumentos e orientações apresentados pelos pesquisadores apresentam algumas contribuições em torna da temática, porém é preciso mais estudos para subsidiar a prática pedagógica das/os professoras/es de Educação Física nas séries iniciais, sendo observado que quanto antes as/os professoras/es agirem, menos fronteiras de gêneros se construíram.

Todos os conteúdos da Educação Física analisados nesta pesquisa caracterizam-se como atividades generificadas, ora relacionados à características atribuídas ao feminino, ora ao masculino. No entanto, ambos os sexos podem e devem vivenciá-los, para assim definirem verdadeiramente seu interesse, pois esses conteúdos contribuem para a formação das/os alunas/os. Desta forma, os estudos levantados apontam a diversificação dos conteúdos como um caminho para o rompimento das fronteiras de gênero. Cabe ao professor/a buscar estratégias para não reproduzir ou reafirmar preconceitos e discriminações, sendo aconselhável problematizar e ressignificar as desigualdades nas relações de gênero.

As diferenças nas habilidades corporais não justificam a superioridade de um sexo em detrimento do outro, essas necessitam ser valorizadas, respeitadas e compreendidas como construídas em grande parte culturalmente, sendo que elas representam instrumentos para o desenvolvimento de princípios de igualdade de direitos, equidade, tolerância, respeito, dentre outros.

Acreditamos que todas/os as/os alunas/os têm o direito de vivenciar todos os conteúdos da Educação Física e não somente o conteúdo esporte, como acontece com freqüência em algumas aulas de educação física, independentemente do sexo da criança. Se alguns conteúdos da disciplina Educação Física geram situações de preconceitos de gênero em nossos alunos ou se alguns conteúdos possuem sentidos generificados, dificultando a 
prática de algumas crianças, a/o professora/o tem aí um ambiente rico para questionamentos, reflexões e discussões sobre questões relacionadas ao gênero, o que poderá levar o grupo a superar tais restrições impostas às crianças no cotidiano escolar e na vida social fora da escola.

\section{REFERÊNCIAS}

1DARIDO, S. C. Educação Física escolar: questões e reflexões. Rio de Janeiro: Guanabara Koogan, 2003.

${ }^{2}$ BRASIL. Ministério da Educação. Lei n. 9.394 de 20 de dez. 1996, estabelece as Diretrizes e Bases da Educação Nacional. Disponível em: www.mec.gov.br.

${ }^{3}$ BRASIL. Ministério da Educação e Cultura. Secretaria de Educação Fundamental. Parâmetros Curriculares Nacionais: terceiro e quarto ciclos do ensino fundamental: apresentação dos temas transversais. Brasília, 1998.

${ }^{4}$ SOUSA, E. S.; ALTMANN, H. Meninos e meninas: expectativas corporais e implicações na educação física escolar. Cadernos Cedes, Campinas, ano 19, n. 48, p. 52-68, ago. 1999.

${ }^{5}$ ARROYO, M. G. Prefácio. In: DAYRELL, J. (Org.). Múltiplos olhares sobre educação e cultura. Belo Horizonte: Ed. da UFMG, 1996. p. 7-8.

${ }^{6}$ SOUZA JUNIOR, O. M.; DARIDO, S. C. Influências da cultura escolar no desenvolvimento de propostas co-educativas em aulas de Educação Física. Motriz, Rio Claro, v. 9, n. 3, p. 143-151, set./dez. 2003.

${ }^{7}$ SOUZA JUNIOR, O. M. Educação Física escolar, co-educação e questões de gênero. In: DARIDO, S. C.; MAITINO, E. M. (Org.). Pedagogia cidadã: cadernos de formação Educação Física. São Paulo: Ed. da UNESP, 2004. p. 71-86.

${ }^{8}$ WENETZ, I. Gênero e sexualidade nas brincadeiras do recreio. 2005. 204 f. Dissertação (Mestrado em Ciências do Movimento Humano) - Escola de Educação Física, Universidade Federal do Rio Grande do Sul, Porto Alegre, 2005.

Conexões: revista da Faculdade de Educação Física da UNICAMP, Campinas, v. 10, n. 3, p. 142-171, set./dez. 2012. 168 ISSN: 1983-9030 
${ }^{9}$ WENETZ, I. Corpo, sexualidade e infância: uma revisão bibliográfica na perspectiva pós-estruturalista na Educação Física e Educação no Brasil (1990-2002). 2003. Monografia (Especialização em Ciências do Movimento Humano) - Escola de Educação Física, Universidade Federal do Rio Grande do Sul, Porto Alegre, 2003.

${ }^{10}$ CRUZ, T. M. Meninas e meninos no recreio: gênero, sociabilidade e conflito. 2004. 194 f. Tese (Doutorado em Educação) - Faculdade de Educação, Universidade de São Paulo, São Paulo, 2004.

${ }^{11}$ PEREIRA, F. A. S. Currículo: Educação Física e diversidade de gênero. 2009. 198 f. Dissertação (Mestrado em Educação) - Pontifícia Universidade Católica de São Paulo, São Paulo, 2009.

${ }^{12}$ TELLES. E. O. O verso e reverso das relações escolares: um olhar de gênero sobre o uso dos tempos em uma escola municipal da cidade de São Paulo. 2005. 180 f. Dissertação (Mestrado em Educação) - Faculdade de Educação, Universidade de São Paulo, São Paulo, 2005.

${ }^{13}$ FERNANDES, L. A. B. Adolescência: a construção das identidades de gênero e de sexualidade. 2005. Dissertação (Mestrado em Ciências Sociais) - Pontifícia Universidade Católica de São Paulo, São Paulo, 2005.

${ }^{14}$ SILVA, J. M. M. Escolarização e produção de subjetividade: capturas e sedições. 1998. 373 f. Tese (Doutorado em Educação) - Pontifícia Universidade Católica de São Paulo, São Paulo, 1998.

${ }^{15}$ RUBIN, G. The traffic in women: notes on the political economy of sex. In: REITER, R. Toward an anthropology of women. New York: Monthly Reviews, 1975. p. 157-210.

${ }^{16}$ SCOTT, J. Gênero: uma categoria útil de análise histórica. Educação \& Realidade, Porto Alegre, v.12, n.2, p.71-94, jul./ dez. 1995. 
${ }^{17}$ GOELLNER, S. V. Mulheres e futebol no Brasil: entre sombras e visibilidades. Revista Brasileira de Educação Física e Esporte, São Paulo,v.19,n. 2, p.143-51, abr./jun. 2005.

${ }^{18}$ SEVERINO, A. J. Metodologia do trabalho científico. 22. ed. São Paulo: Cortez, 2002.

${ }^{19}$ FERNANDES, S. C. Os sentidos de gênero em aulas de Educação Física. 2008. 116 f. Dissertação (Mestrado em Educação Física) - Faculdade de Educação, Universidade Estadual de Campinas, Campinas, 2008.

${ }^{20}$ BROUGÈRE, G. A criança e a cultura lúdica. In: KISHIMOTO, T. M. (Org.). O brincar e suas teorias. São Paulo: Pioneira, 1998. p. 19-32.

${ }^{21}$ MUZSKAT, M. E. Violência de gênero e paternidade. In: ARILHA, M.; RIDENTI, S. G. V.; MEDRADO, B. (Org.). Homens e masculinidades. São Paulo: Ed. 34, p. 215-233, 1998.

${ }^{22}$ PRESTA, M. G. G. Atividades rítmicas na educação física escolar: relações de gênero, preconceitos e possibilidades. 2006. 94 f. Dissertação (Mestrado em Educação) Faculdade de Educação, Universidade Estadual de Campinas, Campinas, 2006.

${ }^{23}$ ALTMANN, H. Rompendo fronteiras de gênero: Marias (E) homens na Educação Física. 1998. 111 f. Dissertação (Mestrado em Educação) - Universidade Federal de Minas Gerais. Belo Horizonte, 1998.

${ }^{24}$ GONÇALVES, V. P. A quadra e os cantos: arquitetura dos gêneros nas práticas corporais escolares. In: CONGRESSO BRASILEIRO DE CIÊNCIAS DO ESPORTE, 2., 2004. Anais... CD-ROOM.

${ }^{25}$ DARIDO, S. C. Futebol feminino no Brasil: do início a prática pedagógica. Motriz, Rio Claro, v. 8, n. 2, p. 43-49, abr./ago. 2002.

${ }^{26}$ STINSON, S. Reflexões sobre a dança e os meninos. Pro-Posições, Campinas, v. 9, n. 2 , jun. 1998.

Conexões: revista da Faculdade de Educação Física da UNICAMP, Campinas, v. 10, n. 3, p. 142-171, set./dez. 2012.170 ISSN: 1983-9030 
${ }^{27}$ HOUAISS, A. Minidicionário Houaiss da língua portuguesa. Rio de Janeiro: Objetiva, 2004.

${ }^{28}$ KUNZ, M. C. S. Dança e gênero na escola: formas de ser e viver mediadas pela Educação Estética. 2003. 441 f. Tese (Doutorado em Motricidade Humana) - Faculdade de Motricidade Humana, Universidade Técnica de Lisboa, Lisboa, 2003.

${ }^{29}$ OLIVIER, J. Das brigas aos jogos com regras: enfrentando a indisciplina na escola. Porto Alegre: Artes Médicas, 2000.

${ }^{30}$ ROMERO, E. A Educação Física a serviço da ideologia sexista. Revista Brasileira de Ciências do Esporte, Campinas, v. 15, n. 3, p. 226-233, jan. 1994.

${ }^{31}$ DAOLIO, J. Da cultura do corpo. 6. ed. Campinas: Papirus, 1995.

${ }^{32}$ CONNELL, R. Gender. Great Britain: Polity, 1990.

${ }^{33}$ DAOLIO, J. A construção cultural do corpo feminino, ou o risco de transformar meninas em “antas”. In: __ Cultura: Educação Física e futebol. 2. ed. Campinas: Ed. da UNICAMP, 2003. p. 107-119.

${ }^{34}$ FARIA JR., A. G. Futebol, questões de gênero e co-educação: algumas considerações didáticas sob enfoque multicultural. Revista de Campo, São Paulo, v. 2, n. 12, p. 17-39, dez. 1995.

${ }^{35}$ ESPANHA. Ministerio de Igualdad. Instituto de la Mujer. Guia PAFIC para la promocion de la actividad física en chicas. Madrid, 2010. 